\title{
Las elecciones presidenciales de 1899 según la prensa política limeña ${ }^{1}$
}

\author{
Jorge García Escobar \\ Universidad Nacional Mayor de San Marcos \\ jgarciae@unmsm.edu.pe \\ María Mendoza Méndez \\ Universidad Nacional de Educación Enrique Guzmán y Valle \\ maria.mendoza@upn.edu.pe \\ Emilio Rosario Pacahuala \\ Universidad Nacional Mayor de San Marcos \\ emiliorosario981@gmail.com
}

\begin{abstract}
RESUMEN
Las elecciones presidenciales son un espacio de amplio debate público, desfogue de pasiones ideológicas, confrontación de ideas; entre otros aspectos que podemos encontrar gracias al papel difusor de la prensa, responsable en describir los acontecimientos acaecidos. Es importante señalar que los diarios jugaron un rol central, especialmente durante los contextos pre-electorales o en los propios comicios, ya sea para forjar la imagen a favor o en contra de algún candidato. En ese sentido, el contraste de información proveniente de diversos periódicos e incluso de las memorias de prefectos, testigos de la época entre otro tipo de fuentes nos permite acercarnos objetivamente a la realidad y de esta forma desmitificar a la llamada República Aristocrática (1899-1919) tildada por algunos historiadores como un espacio de estabilidad social y política. Por el contrario, lo expuesto en la prensa nos muestra un tiempo de mucha tensión y confrontación en los albores del siglo xx. Un ejemplo son las elecciones presidenciales de 1899 el cual estudiaremos a continuación a partir de la descripción realizada por los principales diarios de la capital como El Comercio, El Germinal, entre otros.
\end{abstract}

Palabras clave: Elecciones; prensa; política pública; Partido Civil; Partido Demócrata.

\section{The 1899 Presidential elections according to Lima's political press}

\begin{abstract}
Presidential elections are a space of broad public debate, a vent of ideological passions, confrontation of ideas, among other aspects that we can find thanks to the press diffusing role, responsible for describing occurred events. It is important to point out that newspapers played a central role, especially during pre-electoral contexts or in actual elections, either to forge the image for or against a candidate. On this matter, information contrast from various newspapers and even the memories of prefects, witnesses of the time among other sources, allowed us to approach reality objectively and thus demystify the so-called Aristocratic Republic (1899-1919) labeled by some historians as a space of social and political stability. On the contrary, what is exposed in the press shows us a time of great tension and confrontation at the dawn of the 20th century. An example is 1899 presidential elections, which we study from descriptions made by the main newspapers of the capital city as El Comercio, El Germinal, among others.
\end{abstract}

KeYwords: Elections; press; public politics; Partido Civil; Partido Demócrata.

1 Esta investigación forma parte de un trabajo en torno a la prensa peruana y las elecciones de inicios del siglo xx. 


\section{Introducción}

E 18 de setiembre de 1899 asumió la Presidencia de la República el ingeniero arequipeño Eduardo López de la Romaña, representante del civilismo y los pierolistas. La conquista del más importante cargo de representación política en el país fue después de un largo y agitado proceso iniciado en marzo de ese mismo año. Los comicios electorales inicialmente contaron con la participación de las distintas fuerzas políticas de aquel entonces: el Partido Civil, el Partido Constitucional, el Partido Demócrata, el Partido Liberal y la Unión Nacional; así como de los principales líderes políticos de aquel entonces: el ensayista limeño Manuel González Prada y Ulloa y del plutócrata ariqueño Guillermo Billinghurst quienes eran los voceados para encabezar la oposición que enfrentaría a la alianza cívico-demócrata, la cual triunfó categóricamente en el proceso electoral de 1896; sin embargo estos personajes optaron por automarginarse de los comicios presidenciales.

Uno de los tantos secretos del éxito de los civilistas durante los procesos electorales desarrollados entre 1899 hasta 1916 (con excepción de las elecciones de 1912) fue controlar el aparato electoral; para precisar los civilistas tuvieron la capacidad de manipular los padrones de votantes, los cuales fueron integrados en casi su "totalidad" por personas que sabían leer y escribir además de tener un determinado poder adquisitivo, una valla que era traspasado con facilidad por los adeptos al Partido Civil y el Partido Demócrata más no por las organizaciones opositoras cuya base social estaba conformada por las clases medias, artesanos, obreros entre otros grupos subalternos cuya instrucción educativa era limitada y cuyas rentas mensuales en mayoría era menor a la solicitada por las leyes electorales para engrosar la nómina de votantes. Por tanto, no debe extrañarnos que los presidentes elegidos durante la República Aristocrática (1899-1919) estuvieran "ligados a intereses azucareros o exportadores en general» (Chiaramonti 1995: 316). Además, los civilistas contaban con el capital económico suficiente para realizar una campaña con mayor éxito. Dicho escenario impedía una competencia en iguales condiciones entre grupos políticos, sumémosle a ello la incapacidad de los partidos opo- sitores en no constituir bases de apoyo a lo largo y ancho del territorio patrio.

Las elecciones presidenciales se presentan entonces como un escenario de profuso intercambio de ideas a nivel público, expresión de programas y confrontación de propuestas; entre otros aspectos que fueron perfectamente representados por la prensa limeña. Es importante señalar que los diarios jugaron un rol central, especialmente durante los comicios, ya sea para forjar la imagen a favor o en contra de un candidato. En el presente artículo describiremos el proceso electoral de 1899 a través de los periódicos. Para su análisis utilizaremos el método histórico el cual nos permitirá contextualizar las fuentes de estudio que utilizaremos para describir ese contexto histórico, en este caso los periódicos como: El Germinal, El Comercio, La Integridad y el Libre Pensamiento.

\section{Las reglas del juego}

Entre 1890 a 1899 acontecieron distintos eventos que afectaron el rumbo del país. En el ámbito político se llevó a cabo una guerra civil en 1895, protagonizadas por los partidarios de Andrés Avelino Cáceres versus los simpatizantes de Nicolás de Piérola, este último fue el vencedor y posteriormente elegido presidente del Perú (1896-1899). En el ámbito económico, nuestro país obtiene una notable mejora gracias a la ejecución del Contrato Grace (1886-1889), cuya firma liberó al Perú de la deuda externa acumulada antes y durante el conflicto bélico contra Chile (1879$1883)^{2}$. El darwinismo social ofrecía los instrumentos ideológicos para justificar el pensamiento eugenésico en desmedro de la población subalterna como el caso

2 Los tenedores de bonos encabezados por Michael Grace, quienes habían prestado dinero al Perú antes y durante la guerra del Pacífico solicitaron durante el gobierno de Cáceres (1886-1890) la devolución del dinero. "Grace comprendía que el gobierno peruano no disponía del dinero suficiente para cancelar lo prestado ni mucho menos cubrir sus altísimos intereses, por tanto tenían que otorgar otro tipo de contraprestación que permita saldar la honra pública. Es así que el empresario extranjero solicitaba la obtención de terrenos agrícolas entre otro tipo de exigencias discutidas un ańo antes en las oficinas estatales, en algún café de la época o en los diversos espacios de confluencia pública en donde se llevaría a cabo las negociaciones iniciales» (p 147) Luego de largos debates y 4 años después de discusión en el Parlamento Nacional, finalmente el gobierno peruano y Grace firmarían un trato con las concesiones solicitadas por un espacio de 66 ańos. Para ampliar ello revisar, (Rosario, E./Rosario, J: 2014-145-156.) 
de indígenas, negros e inmigrantes asiáticos quienes representaban demográficamente la gran mayoría de los habitantes ${ }^{3}$. Esta serie de situaciones en el devenir económico, político y social obligaba a reconstituir las leyes en lo que respecta a participación ciudada$\mathrm{na}^{4}$. Mediante editoriales periodísticas y discursos públicos se declaraba lo endeble que hasta la fecha era el sistema electoral. Desde nuestra independencia no se garantizó el respeto a la voluntad popular, muy por el contrario, sobre sus falencias legales y falta de mecanismos efectivos de control por parte del Estado se asienta el beneficio de los grupos particulares para imponer sus intereses tal como lo testimonia Adriana Verneuil quien describe la violencia callejera acontecida durante los comicios de 1875 :

[...] recuerdo que era un sábado y al llegar, nos avisaron que el otro día, no podríamos salir a la calle, por ser elecciones y no exponernos a recibir las balas de los partidarios de Prado o de Montero, como se llamaban los dos candidatos en disputarse la elección, para la presidencia de la República [...] desde ese primer día le fue muy simpático a mi papá, este pueblo que defendía tan valerosamente sus preferencias políticas, aunque le pareció algo brusca la manera de adueñarse de las mesas electorales que habían puesto en la plazuela de la merced frente a nuestro hotel, para recibir los votos del pueblo [...] tres días duraron las elecciones con sus griterías, asaltos y tiroteos respectivos por ambos lados, quedando vencedores los partidarios de don Mariano Ignacio Prado, quien iba a ser elegido Presidente Constitucional de la República, sucediendo a don Manuel Pardo (Verneuil, 1947, p. 44)

Estos argumentos fueron el respaldo necesario para sustentar la reforma electoral de 1896, cuyo objetivo era desaparecer las prácticas violentas durante los comicios. El objetivo principal era convertir a las elecciones presidenciales, congresales y municipales en

3 Para indagar más profundamente sobre el darwinismo social en el Perú ver (García Jordán: 1992: 961-975)

4 Recordemos que el régimen en el poder era el «Partido Demócrata» liderado por Nicolás de Piérola que se «distinguió del resto de las agrupaciones políticas por contar con un programa de gobierno que tenía la intención de establecer la verdad electoral. Esta fórmula, tal y como fue hecha pública en 1889, consideraba imprescindible crear un poder electoral autónomo del resto de los poderes del Estado», por ello no debe extrańarnos que se haya impulsado la Ley Electoral de 1896. En (Peralta Ruiz: 2005: 77) verdaderas fiestas democráticas en donde realmente se exprese la voluntad popular.

Para sus gestores la nueva Ley Electoral era una medida ideal; digna de un país en vías del desarrollo, ya que fortificaba el sistema democrático, respetando los resultados de los comicios y lo que es más importante simbolizaba verdaderamente la expresión auténtica de la ciudadanía. Sin embargo, para los opositores como los miembros del Partido Constitucional: Andrés Avelino Cáceres, Abelardo Gamarra entre otros, esta nueva medida era totalmente excluyente porque no todos los ciudadanos tenían acceso al voto, solo se le atribuye a un determinado sector social además las novísimas leyes generaban el control del aparato electoral por parte de la organización que se encontraba en el gobierno.

Para impedir la llegada de los no decentes (quiere decir los sectores empobrecidos y analfabetos) a los cargos de representación pública se establecieron diversos filtros que habrían de restringir su inclusión en el padrón electoral, uno de los novísimos requisitos para elegir y ser elegido; era ser letrado, además de tener un determinado ingreso económico, situación que contrariaba a la past normativa, la cual consideraba el poder adquisitivo como principal requisito para adquirir los derechos políticos (1861). En la nueva Ley Electoral, la meritocracia se hacía presente; por ejemplo, el candidato al parlamento nacional al no poseer los ingresos monetarios establecidos podía suplir esta carencia con la práctica de una profesión. En apariencia dicha ley impediría que la fuerza de las hordas urbanas y rurales intervenga impunemente en contra de la voluntad ciudadana (Aguilar: 1997). Sin embargo, lo que revolucionaría el sistema electoral peruano en comparación con sus antecesores normativos era la fulminación de la descentralización de poderes.

Las elecciones realizadas antes de 1896 eran organizadas y ejecutadas por los colegios electorales constituidos en las diversas provincias siendo su misión principal el garantizar la instalación de mesas de votación y llevar a la práctica la fiscalización del escrutinio. Finalizado este proceso se suscribía el acta en donde se declararía al ganador del proceso en la zona en disputa; empero, un problema que estuvo presente en los comicios era la dualidad de mesas. Las organizaciones políticas durante el acto de votación instalaban dos mesas, cada una representando a las distintas 
organizaciones políticas generando esta situación distintos resultados. En los siete días que duraba todo el proceso ambas agrupaciones por lo general buscaban por diversos medios la destrucción de la mesa rival lo que gestaba permanentes confrontaciones físicas entre partidarios. Triunfaba en muchas ocasiones aquel que impedía que el otro continúe su propio proceso electoral. Sin embargo, quienes jugaban un rol clave bajo la antigua normatividad eran los peruleros, personas encargadas de atraer potenciales votantes con la promesa de alimentarlos y emborracharlos para posteriormente desfilar por las mesas de votación y respaldar al candidato que les obsequiaba las viandas y bebidas alcohólicas. Esta situación obligaba al Estado a tomar un papel mucho más protagónico en el control y orden de los comicios, siendo responsable de ello la naciente Junta Electoral Nacional.

Dicho organismo estuvo conformado por el gran jurado integrado por siete miembros: tres elegidos por el Poder Legislativo, tres nombrados por el Poder Judicial y uno designado por el Poder Ejecutivo. Entre las facultades de la Junta Electoral Nacional estaba, por ejemplo:

[...] formar el registro general de la República, remitir una copia a la secretaria del congreso para las elecciones de presidente y vicepresidentes, anualmente deberían realizar los cambios en el registro electoral, elegir a los presidentes de las juntas electorales departamentales y la responsabilidad de las funciones electorales 5 .

Esta última descripción nos permite comprobar el amplio poder de dicha organización. Sin embargo, en su flamante estreno durante los comicios de 1899 este ente electoral fue eliminado contradictoriamente por quienes lo crearon. Esa bochornosa situación se dio en razón a que la oposición censuró al presidente de dicho organismo Pablo Olaechea, vinculado al Partido Demócrata. La causa de su veto respondía a que Olaechea no convocaba regularmente reuniones de este órgano colegiado, porqué él y su agrupación se encontraba en minoría y por ende sus designios no lograban el apoyo necesario. Con la exclusión del presidente, la oposición había obtenido la mayoría de los escańos al interior de la Junta Electoral Nacional

5 Funciones de la Junta Electoral Nacional; Ley de elecciones, 20 de noviembre de 1896 generando el temor del oficialismo de salir derrotado en estos comicios ${ }^{6}$. Frente a esta crisis interna el gobierno ordenó el 24 de abril la inhabilitación de la junta en su totalidad. La justificación de Piérola para avalar dicha acción que contravenía toda acción legal era el rol obstruccionista e intrascendente de la Junta Nacional Electoral:

[...] la única atribución que le quedaba era ejecutar la operación puramente material de sortear uno de entre dos escrutadores, cualquiera de los cuales era legalmente hábil operación que podían ejercitar no importaban quien sin afectar en manera alguna la elección 7 .

La Ley Electoral incluso contemplaba los pasos a seguir el mismo día de la realización de las elecciones. En primer lugar, las mesas se instalaban desde la 1 hasta las 4 p. m., durante seis días. De este lapso de tiempo se utilizaban dos días para la elección de diputados propietarios y suplentes, dos días para las elecciones de los senadores propietarios y suplentes y dos días para que los ciudadanos decidan quiénes serían el Presidente y los Vicepresidentes. Diariamente se procedería al conteo y así se acumulaban los votos para definir a los ganadores. Durante el escrutinio los partidos políticos podían enviar personeros como testigos para fiscalizar dicho acto.

En caso de alguna inconformidad con el resultado se podía hacer un reclamo durante las siguientes 24 horas ante los órganos competentes. De comprobar falta alguna se redactaba un escrito al Juez de Paz de la provincia para que estableciera un proceso judicial en contra de los implicados; solo en caso de afectar a la mayoría de los votos se practicaba nuevamente el acto electoral. En caso de un empate entre los candidatos habría de proceder a un sorteo para definir al vencedor. Finalizado el proceso en las provincias se establecía un acta para los archivos como evidencia en donde se describían los pormenores acontecidos durante el acto electoral, la Junta escrutadora enviaba a la secretaría del Parlamento Nacional para contabilizar las boletas y luego al Prefecto, Ministerio de Gobierno y la Cámara de la cámara baja, siguiendo el mismo procedimiento para Senadores.

\footnotetext{
6 El Germinal, 21 de enero de 1899.

$7 \quad$ El Peruano, 28 de julio de 1899
} 
El Germinal, el diario perteneciente a la Unión Nacional, organización política fundada por Manuel González Prada (1899), reconocía que la nueva Ley Electoral de 1896 contemplaba en sus distintos artículos diversos filtros de seguridad que impedían aparentemente el boicot de la voluntad popular; empero en la praxis ello no se cumplió, debido a que el irrespeto de la Ley provendría no solo de las organizaciones políticas, además se detectó acciones del propio Gobierno central, quien incitó al amañamiento de los resultados finales ${ }^{8}$.

Como podemos apreciar la legalidad e ilegalidad fueron ingredientes no solo de los comicios decimonónicos, también estuvieron presentes en los comicios electorales de principios del siglo número veinte, a pesar de la aprobación de la Ley Electoral de 1896.

\section{El Partido Demócrata}

En diciembre de 1879, en pleno desarrollo de la guerra contra Chile, Nicolás de Piérola asumió la máxima magistratura nacional a través de un golpe de Estado en desmedro del hasta entonces Vicepresidente: el coronel Luís la Puerta. Durante el tiempo que Piérola gobernó por primera vez el Perú fundó el Partido Nacional.

Empero, su proyecto de constituir una fuerza político militar capaz de gestar la estabilidad interna de la nación y lograr un resultado beneficioso para el Perú en la guerra fracasaron. La llegada del ejército chileno a Lima obligó a Piérola a abandonar la capital rumbo de la sierra central junto a su comitiva gubernativa. Nicolás de Piérola intentó conformar una Asamblea en Ayacucho (1881) que legitime sus acciones como mandatario nacional; sin embargo, los magros resultados bélicos y la crisis económica provocaron su falta de respaldo y a posteriori su renuncia a la Presidencia de la República, huyendo del país. El ejército chileno terminó por aplacar los focos de resistencia liderados por Cáceres; a la par los chilenos constituyeron un gobierno sumiso a sus intereses, el elegido para encabezar el gobierno que aparentemente entablaría las conversaciones para el cese al fuego y establecería las condiciones de rendición por parte del Perú fue Miguel Iglesias quien convocó a la

8 El Germinal, 21 de enero de 1899
Asamblea de Cajamarca evento al que fue invitado el Partido Nacional, pero dicha organización optó por no participar. En tierras cajamarquinas se redactó y ratificó posteriormente el tratado de Ancón, en cuyos artículos se reconocía la rendición incondicional del Perú frente a Chile. El pierolismo no estuvo contra el régimen iglesista, más aún si «impedía que los civilistas formen un gobierno» (Pinilla 1947: 366), por tanto, no fue en esos momentos una seria amenaza al régimen iglesista. Como podemos apreciar Piérola fue influyente en el devenir nacional, funcionando por mucho tiempo como una especie de «as» bajo la manga que le permitió definir en favor o en contra de un bando en razón a su propio interés.

Sin embargo, la ausencia de Piérola provocó el deceso del Partido Nacional. Su retorno a nuestro país le obligó a constituir una nueva organización que buscase nuevamente fortalecer la relación entre el caudillo y la población. Frente a ello nace el Partido Demócrata como alternativa que permita canalizar a un conjunto de personas opositoras al régimen liderados por Cáceres. Las principales propuestas de la flamante organización era la búsqueda de la estabilidad político-social tanto dentro como fuera de las fronteras nacionales, elecciones directas y la vuelta de la vigencia de la constitución de 1860 .

Gran parte de las aventuras políticas de Piérola tuvieron el apoyo de Guillermo Billinghurst quien por aquel entonces se desempeñaba como canciller en el puerto de Iquique defendiendo las propiedades materiales de nuestros compatriotas, logrando un relativo éxito en su cometido.

La fundación del Partido Demócrata no garantizaba la toma del poder político de manera automática, Piérola tuvo que pasar mil y un obstáculos para alcanzar el trono presidencial. Uno de los principales escollos fue la abierta confrontación con los civilistas. La relación entre ellos fue tensa durante mucho tiempo, incluso durante la ocupación de Lima a mano del ejército chileno, los civilistas coordinarían con el enemigo para dejar fuera de la representatividad política a los pierolistas. Esta dialéctica situación generó que después de la guerra del Pacífico, el civilismo prefiriera apoyar a Cáceres y el partido Constitucional en su ascenso a la presidencia (1886) y marginar una vez más a Piérola. El régimen cacerista tomó una actitud conciliadora con ambos grupos en un primero momento, mientras que encontró a sus principales 
aliados en los gabinetes a los civilistas quienes se ubicarían en las cámaras legislativas, tal como señala Jorge Basadre:

La primera administración cacerista de 1886 a 1890 no fue, en verdad, un gobierno castrense; personajes civilistas intervinieron en la solución de asuntos de esa época, como en el contrato Grace, y tuvieron importante actuación en los ministerios y en el congreso, de gran relieve entonces (Basadre, 1981, p. 61).

Como podemos apreciar durante la gestión de Cáceres se concretó entre ambas organizaciones políticas una especie de pax, si bien cada una mantenía sus objetivos institucionales de poder, por supervivencia momentáneamente se supeditaban a la figura del héroe de la Breńa.

Con el ascenso de Morales Bermúdez tanto los cívicos y demócratas fueron desplazados de las carteras ministeriales para ser reemplazados por los militares, obteniendo el control del Estado, generando un repudio automático por parte de las diversas fuerzas políticas del país, porque a corto plazo no permitían compartir los privilegios del tesoro público con el resto de las organizaciones políticas y a largo plazo evitarían la alternancia del poder. Sin embargo, la muerte de Remigio Morales Bermúdez abría la posibilidad de conseguir el poder político por los canales regulares nos referimos a los comicios electorales; sin embargo, la ambición de Cáceres por volver a manejar las riendas del Perú generó una nueva candidatura, pero este escenario le fue desfavorable porque no tendría el mismo respaldo de su primera elección.

La oposición no se quedó de brazos cruzados ellos elaboraron un frente amplio que combatió al Partido Constitucional. El Partido Democrático ejecutó una alianza calificada por muchos como "contra natura» al unirse con el civilismo dado los conflictos que tuvieron durante mucho tiempo y descrito en párrafos anteriores, de esta manera en 1895 ambas organizaciones se fusionarían para derrotar al cacerismo. Dicha unidad fue celebrada tanto por sus contemporáneos como por generaciones futuras como el caso del escritor iqueño Abraham Valdelomar quien se refiere a: «iLa revolución! ¡El 95! ¡El 95 fue Piérola con su rifle al hombro y Billinghurst con su potro arrogante [...] El perpetuo luchar de nuestros padres contra tiranos analfabetos y bárbaros» (Valdelomar, 2001, p. 549), apreciando el protagonismo que asumió el califa y sus seguidores en contra de los militares!

Derrotado Cáceres tanto civilistas como demócratas mantuvieron la alianza hasta 1903. Sin embargo, «El Califa» no tuvo la capacidad suficiente para fortificar su organización política, el no constituir redes políticas y clientelistas que le generen fidelidad alrededor de su persona y también respecto al partido político le trajo serias consecuencias al consolidar su organización a largo plazo. Finalmente, el golpe mortal que dejó agonizando al Partido Demócrata fue la ruptura con Augusto Durand, importante militante demócrata, que fue impedido de presidir la Cámara de Diputados, asumida por Carlos de Piérola. Esta situación generó serias fracturas al interior de las filas demócratas, atomizando aún más su poder y capacidad de influencia en el Poder Legislativo.

Frente a la falta de liderazgos al interior de las filas demócratas para afrontar las elecciones presidenciales, Piérola decide ampliar el frente, converger con otras fuerzas políticas. Los grupos que participaron en este conglomerado fueron: la Unión Cívica de Mariano Valcárcel, la Unión Nacional, el Partido Constitucional y el propio civilismo. Esta reunión se autotituló como La Convención; sin embargo fracasó al momento de definir el candidato a la presidencia que representa toda esta pléyade de intereses. Aunque fueron los civilistas quienes boicotearon internamente este proceso al tildar de extremistas a los constitucionalistas y los unión-nacionalistas, generando su retiro de esta coalición que en un inicio se ideó pensando en determinar un mandatario producto de un consenso entre las diversas fuerzas políticas, fue todo lo contrario a la definición de un hombre producto de las conversaciones entre los miembros más importantes del Partido Civil y el Partido Demócrata.

Desde luego hubo resistencias al interior del civilismo para continuar la alianza con los demócratas y ceder la primera magistratura a un personaje de consenso. Finalmente, el Partido Civil aceptó esta fórmula porque "conservaban su mayoría en el parlamento y su influencia en los negocios públicos» (Miró Quesada, 1961, p. 283). Para generar un consenso el candidato del civilismo Manuel Candamo dio un paso al costado en beneficio de la unidad entre ambas fuerzas políticas. Finalmente, el candidato de la alianza civil-demócrata fue Eduardo López de la Romaña: 
Ello lo convertía en el personaje adecuado para llevar a efecto el pacto entre civilistas y demócratas quienes ya se enfrascaban en duras pugnas previendo la sucesión presidencial. El carácter conservador y religioso de Romańa ayudaba a apaciguar los ánimos, especialmente al interior del Partido Demócrata (Gonzales, 2005, p. 182).

Era la persona idónea para catalizar las expectativas de civilistas y demócratas pues desanimaría «....ambiciones perturbadoras, a debilitar apetitos demasiados vivos, a ofrecer una garantía de justicia a todos los partidos y círculos y a reafirmar el régimen de moralidad administrativa abierta en la revolución de marzo ${ }^{9}$ ".

Los civilistas se conformaron por colocar en la 1ra vicepresidencia al abogado Isaac Alzamora. De esta manera la alianza de gobierno forjó las condiciones para retener el Poder Ejecutivo, más aún al apoyarse de una figura carismática como López de la Romaña quien tuvo reacia oposición de diversos diarios e intelectuales de la época.

Una de las formas de mermar la imagen de López de la Romańa era presentándolo como un títere, un ser sin capacidad alguna de mando, supeditado al interés del pierolismo, gran parte de estos adjetivos fueron diseñados por José Santos Chocano (Chocano, 1940, p. 184). A pesar de estas fulminantes críticas la candidatura de este personaje contó con el respaldo necesario, por ejemplo, desde Arequipa las bases del Partido Demócrata le declaraban su respaldo incondicional. Incluso en un pronunciamiento de apoyo que serviría para aplacar las críticas de los opositores. Sobre esos beneficios del consenso se indicó:

estamos acostumbrados a dejar que los caudillos se nos impongan, y tal disciplina contribuía de seguro a que algunos encuentren extrańa la presentación de un hombre sin aspiraciones que no ha solado en dominar a sus conciudadanos. Pero hay que considerar, además que los descontentos de cuanto se hace y de cuando ocurre se formaran tampoco con ninguno de los personajes que han actuado largo ańos en la marcha del Estado ${ }^{10}$.

El diario El Libre Pensamiento se convertiría en una trinchera opositora al candidato cívico-demócrata

9 Al civilismo, La Ley, 2 de enero de 1899

10 El Comercio 3 de enero de 1899 porque su elección significaría que el «Perú retroceda hasta la época del coloniaje, a los infaustos días de la Real Audiencia, del virrey, del inquisidor en que se achicharraba a la gente» ${ }^{11}$. Sin embargo, sus titulares editoriales o notas informativas finalmente no causaron ningún daño a la estrategia pre electoral oficialista, más aún su candidatura se convirtió incluso en la única alternativa para la alianza de gobierno debido a que no existía otro candidato al interior de las canteras del Partido Demócrata que eclipsara a López de la Romańa.

\section{Divisiones internas}

Guillermo Billinghurst nació en la otrora provincia peruana de Arica el 27 de julio de 1851, dicho personaje generó una excelente admiración incluso entre sus rivales políticos como en el caso de José Santos Chocano:

un hombre inteligente, enérgico, rectilíneo. Su carácter era de una franqueza excesiva, que le hacía con frecuencia romper las fórmulas y lastimar las susceptibilidades enfermizas. Desnudaba él su espíritu en cuanto decía, sin reservar sus opiniones ni disimular sus apasionamientos (Chocano, 1940, p. 184).

Pedro Dávalos y Lisson nos presenta a un hombre apasionado en sus actividades públicas: «un hombre inquieto y sencillo, colérico e intransigente, su antipatía y repudio al civilismo, lo ocultaba, pero por razones políticas...» (Dávalos y Lisson, 1923, p. 8). En tanto Carlos Miró Quesada señala la actividad empresarial del personaje en mención:

salitrero próspero y heredero de la fortuna de un hermano también rico, tenía dinero suficiente para una campaña y arrastraba las simpatías populares. Era violento, pero bonachón, con arranques de ira y comprensiones generosas. Fue un caudillo muy fugaz, sin la permanencia de Piérola ni el arraigo de Cáceres. Yo lo llamaría caudillo de circunstancias, ya que no formó un partido ni dejó estela alguna. (Miró Quesada, 1961, p. 406).

11 El Libre Pensamiento, 18 de febrero de 1899 
Como apreciamos en los tres autores citados Guillermo Billinghurst era una persona que tenía los medios económicos y la capacidad administrativa más no el carisma suficiente para atraer las pasiones y los odios de la población. El complemento que supliría la limitación de Billinghurst fue Nicolás de Piérola, La aventura política de ambos personajes comenzó desde la captura de la embarcación El Talismán en 1873, cuyo objetivo era derrotar al régimen de Manuel Pardo; sin embargo, ambos serían derrotados y el empresario ariqueño huyó hacia Bolivia.

El gobierno civilista de 1875 le asestó un duro golpe económico a los intereses de Billinghurst cuando estatizarían el salitre. Posteriormente durante la guerra del Pacífico, Guillermo Billinghurst participó en la Defensa de Lima (1881), en donde es herido y hecho prisionero; después de pagar un cuantioso rescate sale liberado. Durante la reconstrucción nacional asume, el papel de plenipotenciario defendiendo los intereses que se encontraban en las provincias cautivas. Volvió a luchar junto a Nicolás de Piérola por la toma del poder, esta vez apoyados por el civilismo, todos ellos en contra de Cáceres en 1895, quienes después de una sangrienta guerra lo derrotarían. Piérola asume la Presidencia de la República un año después, en tanto Billinghurst ingresa como Primer Vicepresidente de la República. La admiración y el respeto por parte de Billinghurst a Piérola era tal que incluso se autocalificó como la "cola de la figura política más prestigiosa del Perú» ${ }^{12}$.

Durante los comicios presidenciales de 1899, Piérola había designado a un sucesor en coordinación con sus aliados los civilistas; Eduardo López de la Romańa,

Ello lo convertía en el personaje adecuado para llevar a efecto el pacto entre civilistas y demócratas quienes ya se enfrascaban en duras pugnas previendo la sucesión presidencial. El carácter conservador y religioso de Romańa ayudaba a apaciguar los ánimos, especialmente al interior del Partido Demócrata (Gonzales, 2005, p. 182).

El candidato natural del Partido Demócrata era Guillermo Billinghurst, sin embargo fue marginado por el propio Nicolás de Piérola. Como el propio

12 Carta pública dirigida por Guillermo Billinghurst. En: El Comercio, 9 de septiembre de 1892 .
Billinghurst señala en una misiva, en la cual expresa que este se habría convertido en "una amenaza para la obra política» ${ }^{13}$ del pieriolismo. Su posición generó el distanciamiento con otros miembros del partido «los Boza, Bentín, Olaechea, Normand, Obin, Bustamante y Salazar y otros magnates del círculo, recordaban con desafecto asperezas y diferencias de opiniones tenida con él». (Dávalos y Lisson, 1930).

Incluso personajes de la oposición como Manuel González Prada no se mantuvieron al margen de comentar los problemas internos del Partido Demócrata:

En resumen, el telegrama encierra mucho de bueno porque desprestigia tanto al Partido Demócrata como a su jefe, pero eso no impide que sea repugnante y odioso ni que inspire un profundo desdén hacia el individuo que le ha firmado, Cuando un hombre se ha constituido en alma de una agrupación, cuando ha comprometido intereses y removido pasiones, no tiene derecho de disponer libremente de su persona para salir de la escena, consumando actos impremeditados, violentos y más que nada, egoístas ¿qué idea se ha formado Billinghurst de sus partidarios cuando les abandona y sacrifica tan fácilmente? Este hombre es el capitán que en la hora del peligro se salva dejando que el buque naufrague con pasajeros y carga, peor aún, es el acerado que a la aproximación de la quiebra se escapa llevándose su capital y dejando en la estacada a sus pobres asociados. (González Prada, 1931, p. 67)

Autoexiliado de dicha organización Billinghurst decidió retirarse del país mientras las elecciones políticas eran ganadas por el civilismo, posteriormente regresaría y sería elegido alcalde de Lima a emprender una lucha contra el Partido Civil en 1912.

\section{Los comicios electorales}

Las elecciones de 1899, las últimas del siglo XIX, presentaban un candidato único. El diario El Comercio señalaba lo atípico de estos comicios y por tanto desde allí se infería que no podrían llamarse elecciones en un sentido tradicional, donde encontrábamos distintos partidos aspirando a convertirse en el grupo

13 El Germinal. 7 de enero de 1899. 
que controle el Poder Ejecutivo, sino un referéndum en donde se pondría a prueba volver a otorgarle la confianza de la nación «a un régimen de gobierno que funda en apoyo de ella su único título a la existencia ${ }^{14}{ }^{4}$. Esta situación obligaba a los ciudadanos a elegir entre respaldar el orden constitucional o sumergirse en la anarquía. Como apreciamos El Comercio tomó una posición en favor del candidato de la alianza cívico-demócrata por considerarlo una figura que resguardaba el statu quo y la estabilidad política en beneficio de la nación.

Pero no solo en este proceso electoral se disputaba el sillón presidencial; un tercio de las curules parlamentarias también se encontraban en disputa. Uno de los aspirantes al Parlamento Nacional sería el escritor Abelardo Gamarra quien bajo el lema «mano política y más patria» presentaba sus propuestas para ser electo representante por el departamento de La Libertad. Una ventaja en favor de este personaje era contar con el apoyo de un diario como La Integridad, lo que le permitió tener una cercanía mayor con el potencial votante ${ }^{15}$, finalmente Gamarra logrará su objetivo de convertirse en parlamentario.

Sin embargo, el peligro que amenazaban el proceso electoral y que preocupaba a la alianza cívicodemócrata del boicot era la ausencia de electores, frente a ello El Comercio como fiel aliado del partido de gobierno lanzaban una agresiva campaña para incentivar la participación ciudadana:

ahora, por lo que a la situación respecta, nunca ha sido más vivamente sentida la necesidad de que el mayor número posible de ciudadanos intervenga en las elecciones por lo mismo que el candidato designado no es un caudillo político se teme que las masas no lo reciban con entusiasmo, y que, por esta causa, obtenga relativamente, pocos $\operatorname{votos}^{16}$.

Pero ello no era suficiente, López de la Romaña utilizó los distintos medios de comunicación para popularizar su imagen y generar en la ciudadanía la confianza para respaldarlo electoralmente, más aún tenía que constituir medios de defensa frente a los ataques vertidos por González Prada y el cacerismo. Pero todos estos planes se frustraron al no contar con

$14 \quad$ El Comercio, 8 de marzo de 1899.

15 La Integridad, 7 de enero de 1899.

16 El Comercio, 13 de marzo de 1899. el respaldo económico para cubrir los gastos propios de una campaña proselitista, pero ¿Quién asumiría esas responsabilidades? Esta situación provocó serios problemas al interior de la alianza cívico-demócrata, especialmente entre Romaña y Piérola este último acusado de evadir el tan esperado apoyo monetario; finalmente los civilistas fueron los más importantes patrocinadores debido a que su capacidad adquisitiva era mayor:

el señor Romaña solicitó del señor Piérola la entrega de 25,000 soles para sufragar a los desembolsos que le demandasen sus trabajos eleccionarios en el Sur de la República y ante la negativa irrevocable del jefe del Estado ocurrió por esta suma donde los señores Olaechea y Normand y al Banco del Perú y Londres quienes se le proporcionaron en calidad de préstamo (Basadre, 2000, p. 2370).

No debe extrañarnos por ende la preferencia por parte de López de la Romańa en favor de las facciones civilistas desde el primer año que asumió la más importante magistratura del país porque ellos le prestaron un respaldo económico sólido durante toda su campańa. Más aún si se necesitaba todo el apoyo necesario por contrarrestar las críticas.

Una forma de combatir esas leoninas críticas era vetar la presencia de los opositores en los grandes medios de comunicación, como el caso de González Prada. Los pocos diarios que estaban a servicio de la oposición política como El Libre Pensamiento ${ }^{17}$ y El Germinal los cuales sufrieron el abuso por parte del gobierno de turno al destruir la imprenta en donde ambos reproducían sus ejemplares ${ }^{18}$.

La campaña comenzó oficialmente desde el 25 de marzo. Los primeros pronunciamientos de adhesión en favor de la alianza cívico-demócrata aparecieron en la ciudad de Trujillo ${ }^{19}$. A pesar de la excesiva confianza el diario civilista La Ley veía latente el peligro de no llegar a la cantidad mínima de votos requeridos, por ende realizó una campaña más agresiva, sus notas periodísticas proponían no solo dedicarse dos días a las elecciones presidenciales, tal como es-

17 El Libre Pensamiento», era el órgano de prensa de la «Liga de Libre Pensadores del Perú», el cual había sido impulsado por la "Gran Logia del Perú», su director era Christian Dam, cuya visión era anticlericalista.

18 El Libre Pensamiento, 4 de marzo de 1899

19 El Comercio, 27 de marzo de 1899 
tipulaba la Ley; se proponía utilizar los 6 días en que consignaba la votación ${ }^{20}$, quiere decir copar los días que utilizaban para los comicios congresales y vicepresidenciales y de esta manera asegurar el respaldo al candidato único.

Otro problema mayúsculo era que el candidato a la presidencia tuvo poco arraigo en la población, denotándose en las manifestaciones proselitistas donde el arraigo popular era endeble. Frente a esta situación el diario El Comercio arrecio su campaña en favor del candidato cívico-demócrata, incluso tuvo que lanzar públicamente sus propuestas de gestión:

creemos oportuno dar una idea del espíritu altamente emprendedor y progresista que lo anima, dando a conocer sus ideas sobre su programa en materia de adelanto material e industrial. Favorecidos con su caballerosa amistad le oímos expresarse en el sentido que su administración sería puramente de labor material. Que su esfuerzo se concentraría muy en particular a la irrigación, colonización europea, prolongación de ferrocarriles, construcción de puentes y caminos y propagación de la instrucción en un orden elemental óseo el que la raza indígena adquiera a la vez en todo el Perú los conocimiento del saber, leer y escribir ${ }^{21}$.

En tanto los vecinos ilustres de Tayacaja, provincia de Huancavelica, proclamaron a López de la Romaña como el candidato a confiar y quien debía asumir el cargo de Presidente de la República ${ }^{22}$. Al parecer la llamada de atención por parte de asesores, comando de campaña y público en general surtió efecto. Es así como la campaña proselitismo se intensificó por parte de López de la Romaña quien recorrió diferentes partes del país, recibiendo el respaldo de los grupos civilistas como de las facciones demócratas. Una de las más importantes visitas fue realizada en el puerto del Callao, contando con una multitudinaria asistencia, en respuesta de lo cual el candidato presidencial señalaba en un emotivo discurso:

todo me prueba hoy que mis esperanzas se realizan porque esta espontánea manifestación me prueba que los civilistas y los demócratas unidos en abrazo último llenan sus propósitos con el entusiasmo

$20 \quad$ La Ley 28 de marzo de 1899

21 El Comercio 9 de mayo de 1899

22 El Comercio, 8 de abril de 1899 que nos obra el triunfo, para trabajar de consumo la grandeza y glorias de la República continuando la obra comenzada de 1895.23

Inmediatamente López de la Romaña decide abordar un tren rumbo a la ciudad capital llegando hasta la estación Desamparados, en donde es recibido por miles de personas — relata el periodista - inmediatamente el candidato decide comenzar un desfile por calles de la Pescadería, Plaza de Armas, Portal de Escribanos, Mercaderes, Espaderos, Merced y Baquíjano. Pero su encuentro con las multitudes no culmina, se dirige a calle las Divorciadas, en donde aprovechará la concentración de sus simpatizantes y de los curiosos para proclamar otro discurso en nombre del pueblo arequipeño, de donde era natural. En dicho pronunciamiento señalaba que a pesar de que su candidatura era producto de una alianza, no todas las vacantes para la senaduría y diputaduría fueron definidas por él: «los partidos interesados han tenido también completa libertad de acción, sin que yo haya recomendado a uno solo de mis amigos políticos» ${ }^{24}$. Este discurso se aprovechó para dar algunas de sus propuestas como la libertad de Tacna y Arica y la junta del dinero para su rescate.

En esos momentos se informaba que, en la ciudad de Huancayo, las fuerzas de la coalición demócrata civil, representadas por los candidatos Raez y Caballero, derrotaron a los señores Jiménez y Baldeón, a pesar de que estos últimos inscribieron indios de Paccha para que los respalden.

Frente a la impotencia de los grupos opositores por no detener las progresivas victorias del civilismo generaron el intento de boicotear las elecciones por parte de los seguidores de Cáceres y González Prada. Estas reacciones fueron apreciadas en las provincias de Tayacaja y Pampas, esta última ciudad cusqueńa donde los militantes del Partido Constitucional atacaron a los integrantes del Partido Demócrata. De esto era informado el director de gobierno José Oliva quien señalaba que el prefecto Delfín Vidalón amenaza al pueblo con "degüello y fusilamientos» ${ }^{25}$, como podemos apreciar la violencia llegaba a extremos a tal punto de amedrentar a la población. Pero no fueron los únicos lugares en donde se pondrían

23 El Comercio, 17 de abril de 1899

24 Ibid.

25 El País, 4 de abril de 1899 
de manifiesto la violencia. Algunos problemas también fueron detectados en Huancavelica y Cerro de Pasco a raíz de la eliminación de la Junta Electoral Nacional ${ }^{26}$, situación contraria es la que informan en Ayacucho en donde la participación por parte de la población fue masiva ${ }^{27}$.

Las denuncias en contra de la alianza cívico-demócrata giraba en torno al control de las boletas de votación, la manipulación del padrón electoral y la aparición de votantes fantasmas, situación que no fue colocada en los titulares de los principales diarios capitalinos. Ello era producto de la débil reacción por parte de la oposición, debido a que no contaba con medios de prensa efectivo, sumado a ello la situación de sus líderes quienes se encontraban fuera del país o con problemas judiciales.

Si debemos resaltar que la reacción de la oposición política en la capital también fue endeble, incluso la no instalación de las mesas radicaba en problemas de organización más que intentos de boicot tal como señalaba El Comercio:

de las 34 mesas receptoras de sufragios que debía instalarse solo han funcionado 30. Las que no han hecho son las siguientes: la de la Plazuela del Teatro por inasistencia del doctor don Eulogio Romero y haberle faltado el registro de inscripciones; la de la Plazuela de Santa Ana por no haber concurrido los señores Miguel Delgado y Luis Duarte y Valladares; la de la plazuela de Cocharcas por haber recibido su presidente el doctor Bellido, un nombramiento equivocado para la Plazuela de el Carmen, y de la Plazuela de San Pedro por diversos incidentes ${ }^{28}$.

Estos incidentes, típicos incluso de las elecciones de inicios del siglo $\mathrm{xX}$ no fueron impedimento para su desarrollo, incluso los diarios informaban día a día el conteo, teniendo como resultado el respaldo electoral hacia Eduardo López de la Romańa quien encabezaba las preferencias en los distritos de Barranco, Miraflores y Chorrillos. En otros puntos del país como el Callao la situación anómala debido a la poca presencia de electores:

26 El Comercio, 15 de mayo de 1899

27 El Comercio 19 de mayo de 1899

28 El Comercio 25 de mayo de 1899 estas mañana temprano se colocaron en las ocho plazuelas designadas para la votación. Unas pequeńas mesitas de no feo aspecto, pro en las que apenas cambian los útiles de escritorio: tres sillas y una curiosa ánfora de lata, en forma de porongo para leche, completaban el menage electoral [...] Las plazas han estado desiertas casi todo el día, y solo han sufragado unos cuantos, pues la mayoría de los ciudadanos como ni donde votar. A pesar de que el corresponsal de La Ley en este puerto dice que los directores de los partidos coaligados han acordado hacer saber a sus afiliados que pueden dirigirse donde sus respectivos jefes para recibir instrucción, es lo cierto es que aquí nadie conocer a esos jefes, ni se tiene noticia de que los comités de los partidos civil y demócrata hayan sesionado para ocuparse de las elecciones que han principiado en el día de manera que no es de extrañar sea hoy relativamente insignificantes la votación ${ }^{29}$.

Para el 26 de mayo El Comercio ya ofrecía un breve conteo de los votos generales en toda la República: Eduardo López de la Romaña: 766, primer Vicepresidente Isaac Alzamora: 745, segundo Vicepresidente Federico Bresani: 761. A manera de muestra significativa tenemos que personajes como Manuel González Prada obtendría apenas un voto en la provincia de Andahuaylas ${ }^{30}$.

Las denuncias sobre irregularidades electorales continuaban inundando los titulares de los diarios con las voces de protesta que manifestaban cuando se intentaba destruir mesas de votación. Por ejemplo, en Cerro de Pasco la polémica sería tan fuerte que ingresarían los miembros de las autoridades locales quienes anularon mesas en plena votación para instalar a sus propios miembros y de esta manera lograron afectar la participación de toda la ciudadanía ${ }^{31}$. Situación similar en Piura, donde el boicot en contra de la coalición era frustrado por la Junta Departamental Electoral quien limitó el ingreso de ciudadanos a ejercer su derecho democrático.

A pesar de los intentos por parte de la oposición política para impedir el desarrollo electoral no consiguieron sus objetivos. Los resultados de dichas elecciones cuyo registro arrojaba una cifra de 108,597 ciudadanos fue la siguiente: «Romaña apareció con 55918 votos, Candamo 1337, González Prada 549,

29 El Comercio 25 de mayo de 1899

30 El Comercio 26 de mayo de 1899

31 La Integridad, 17 de junio de 1899 
Billinghurst 129 y cifras menores correspondieron a Andrés Avelino Cáceres, Santiago Figueredo, Mariano Nicolás Valcárcel y Carlos de Piérola» (Basadre 2000: 2370). Lo que generaba la victoria de nuestro personaje y por ende la apertura de la llamada República Aristocrática.

\section{Conclusiones}

Llegamos así al final del proceso electoral con un ganador claro y mayoritario, pese a los problemas e incidentes acaecidos, los mismos que fueron retratados por la prensa escrita limeña.

Piérola el 28 de julio de 1899, en su mensaje al país,el cual sería el último de su gestión señalaba lo bien que se había llevado acabo dicho evento «el pueblo peruano llamado a las ánforas en votación directa y pública ha ido a ellas con tranquilidad y orden ejemplar; en número que no tiene antecedente en nuestra historia». Pero también fiel a su estilo no dejaba de criticar a sus opositores aquellos «que todavía viven en un pasado que ha concluido felizmente juzgaron que les sería lícito frustrar la elección y lanzar al país a situación propicia de revuelta ${ }^{32}$.

Después de la victoria de López de Romaña el lunes 14 de agosto se efectuó su proclamación como Presidente de la República con los votos de 39 senadores a favor y tres en contra, y con 83 diputados a favor y 16 en contra. Esto generó que su ingreso a la casa de Pizarro sea en condiciones estables, ahora asumiría las riendas de un país, pero estaba demostrado que esta fórmula de mermar los medios de prensa rival, amedrentar a sus rivales y restarle capacidad económica se convirtió en ingredientes que utilizaron en los siguientes procesos electorales donde triunfaron.

\section{Bibliografía}

Águila, Alicia del (1997). Callejones y mansiones. Espacios de opinión pública, redes sociales y politicas en la Lima del 900. Lima: Pontificia Universidad Católica del Perú.
Aguilar, Roisida (2002). Las elecciones de hace un siglo. La Junta Electoral Nacional de 1896-1912. Lima: Oficina Nacional de Procesos Electorales. Documento de Trabajo $\mathrm{N}^{\circ} 4$.

BASADRE, Jorge (1980). Elecciones y centralismo en el Perú. Lima: Centro de Investigación de la Universidad del Pacífico.

Basadre, Jorge (2000). Historia de la República del Perú. Lima: La República/Universidad Ricardo Palma.

Chiaramonti, Gabriella (1995). Andes o nación: la reforma electoral de 1896 en Perú. En: Antonio Annino (coord.). Historia de las elecciones en Iberoamérica (siglo $X I X)$. México D. F.: Fondo de Cultura Económica.

Chocano, José Santos (1940). Memorias. Las mil y una aventuras. Santiago de Chile: Editorial Nacimiento.

Contreras, Carlos y Marcos Cueto (2000). Historia del Perú contemporáneo. Lima: Red para el desarrollo de las ciencias sociales.

Dávalos y Lisson, Pedro (1930). Diez años de historia contemporánea (1899-1908). Gobiernos de Piérola, Romaña, Candamo, Calderón y Pardo. Lima: Librería e Imprenta Gil.

Dulanto Pinilla, Jorge (1947). Nicolás de Piérola. Lima: Compañía de Impresiones y Publicidad.

Gonzales, Osmar (2005). El gobierno de Guillermo E. Billinghurst. Los origenes del populismo en el Perú (19121914). Lima: Fondo Editorial de la Biblioteca Nacional del Perú.

González Prada, Manuel (1924). Horas de lucha. Callao. 2da edición. Tipografía Lux.

González Prada, Manuel (1976). El honrado y el devoto. En: Propaganda y ataque. Lima: Editorial Petro Perú

Miró Quesada, Carlos (1961). Autopsia de los partidos políticos. Lima: Ediciones páginas peruanas.

Rosario, Emilio (2010). Prensa política. La «Unión Nacional» y el Germinal (1899-1902). En: Investigaciones Sociales, N.o 21. Lima.

Valdelomar, Abraham (2001). Diálogo sobre manido tema. En: Obras completas. Lima. Tomo II. Ediciones PetroPerú.

Villarán, Manuel Vicente (1962). Costumbres electorales. En: Manuel Vicente Villarán. Páginas escogidas. Lima: s/edit. 